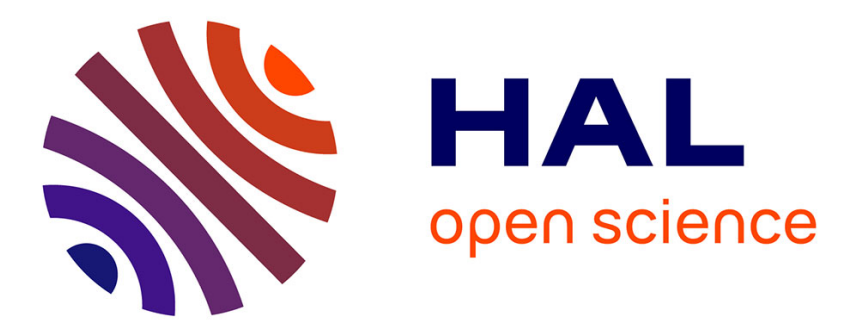

\title{
Performance specifications and analysis of a variable speed synchronous generator witha diode rectifier for the all electric aircraft using the Hinf control approach
}

Matthieu Sautreuil, Olivier Sename, Delphine Riu, Nicolas Retière

\section{- To cite this version:}

Matthieu Sautreuil, Olivier Sename, Delphine Riu, Nicolas Retière. Performance specifications and analysis of a variable speed synchronous generator witha diode rectifier for the all electric aircraft using the Hinf control approach. ECC 2009 - European Control Conference, Aug 2009, Budapest, Hungary. hal-00396273

\section{HAL Id: hal-00396273 \\ https://hal.science/hal-00396273}

Submitted on 17 Jun 2009

HAL is a multi-disciplinary open access archive for the deposit and dissemination of scientific research documents, whether they are published or not. The documents may come from teaching and research institutions in France or abroad, or from public or private research centers.
L'archive ouverte pluridisciplinaire $\mathbf{H A L}$, est destinée au dépôt et à la diffusion de documents scientifiques de niveau recherche, publiés ou non, émanant des établissements d'enseignement et de recherche français ou étrangers, des laboratoires publics ou privés. 


\title{
Performance Specifications and Analysis of a Variable Speed Synchronous Generator with a Diode Rectifier for the All Electric Aircraft Using the $\mathrm{H} \infty$ Control Approach
}

\author{
M. Sautreuil, O. Sename, D. Riu, N. Retière
}

\begin{abstract}
This paper deals with the modeling and control of an electrical source for the future "All Electric" aircraft. It is constituted by a rotor wounded synchronous generator and a diode rectifier feeding the DC power system. Using $\mathrm{H} \infty$ control theory, this paper shows that usual disturbance rejection standards can not be met with such an electrical power source and new standards should be defined. Simulations on an exact nonlinear model of the power source are used for control validation.
\end{abstract}

\section{INTRODUCTION}

$\mathrm{W}$ ITH the development of reliable and efficient power electronics converters, aircraft power networks have been considerably changed. First evolutions concerned the replacement of hydraulic and pneumatic devices by electrohydraulic and electro-pneumatic loads in the "More Electric" aircraft. In these aircrafts, the electrical power is distributed mainly through $\mathrm{AC}$ buses and includes many $\mathrm{AC} / \mathrm{DC} / \mathrm{AC}$ conversion stages to feed the motor loads. With the "All Electric" aircraft, AC/DC conversion stages are suppressed and the electrical power is distributed through a DC bus. This evolution was initiated with the European "Power Optimized Aircraft" project, followed by the current "More Open Electrical Technologies" project in which this work lies [2].

In [1], a first "All Electric" structure is studied from a DC voltage performance point of view. The electrical power source is directly derived from the "More Electric" structure and is shown in Fig. 1.

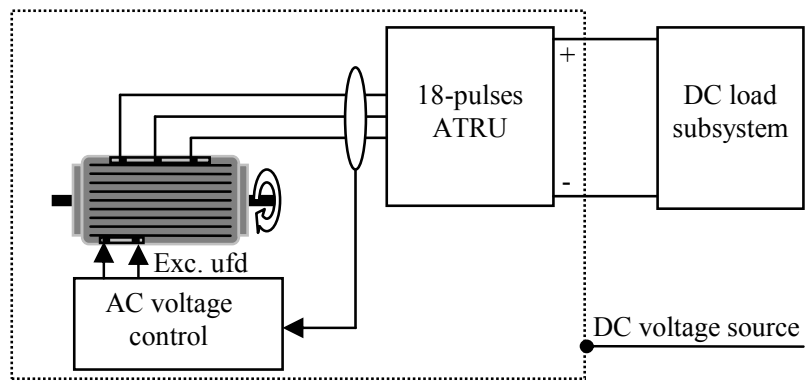

Fig. 1: Power source with Auto Transformer Rectifier Unit [1]

Manuscript received October 15, 2008.

M. Sautreuil, D. Riu and N. Retière are with the Grenoble Electrical Engineering Laboratory (G2ELab), Grenoble, France. (e-mail: matthieu.sautreuil@g2elab.inpg.fr,delphine.riu@g2elab.inpg.fr,nicolas.reti ere@g2elab.inpg.fr).

O. Sename is with the Gipsa Laboratory, department of automatic control, Grenoble, France.(e-mail: Olivier.sename@gipsa-lab.inpg.fr).
The AC side voltage is controlled with a simple PI controller and the analysis in [1] shows that this simple control allows the respect of the disturbance rejection performances imposed by the standards on the DC side. However, the 18pulses ATRU is a heavy device and other source structures are studied for the future "All Electric" aircraft.

In this paper, the authors study the control design of a lighter power source for the "All Electric" aircraft. It is constituted by a $209 \mathrm{kVA}$ synchronous generator with a diode rectifier feeding the DC load. The DC voltage is controlled through the excitation voltage of the synchronous generator (Fig. 2). The stator electrical frequency (fe) depends on the rotor speed, and varies from $360 \mathrm{~Hz}$ to $800 \mathrm{~Hz}$. However, because the shaft speed varies slowly regarding electrical time constants, the system is assumed to be Time Invariant in this paper. Our aim is to evaluate if the usual disturbance rejection specifications can be met with this power source structure. If not, new standards should be proposed. The $\mathrm{H} \infty$ control theory is applied to obtain an optimal controller towards disturbance rejection control objectives. These objectives will have to be met for several operating conditions corresponding to the variable frequency operation of the generator.

The paper is organized as follows. In Section II, the linear model of the system is first derived. The control specifications are then defined. One of these specifications is the respect of the usual disturbance rejection standard. Section III proposes the design of a $\mathrm{H} \infty$ controller at a given operating point $(\mathrm{fe}=400 \mathrm{~Hz})$ and a performance analysis over all the operating conditions is performed. Section IV will conclude on the feasibility of a control for the performance specifications given in section II. It is shown that the standards, which impose the performances from a disturbance rejection point of view, should be modified if this source is finally used in the "All Electric" aircraft.

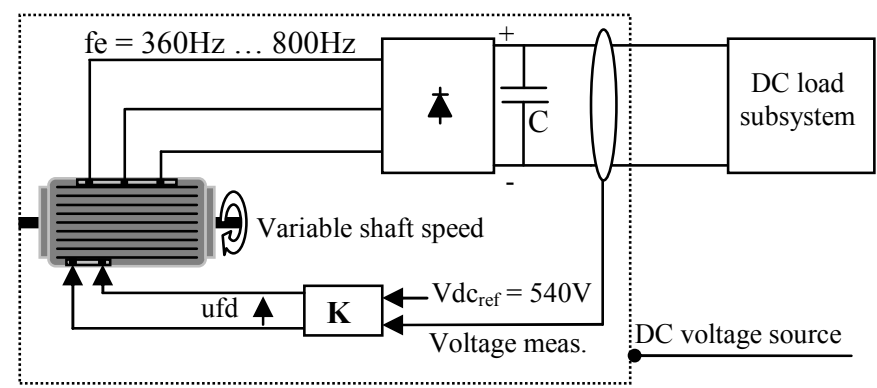

Fig. 2: Studied Power source 


\section{MODELING AND CONTROL SPECIFICATIONS}

\section{A. Modeling}

1) The synchronous generator model

The generator equations are written in the $(\mathrm{d}, \mathrm{q}, 0)$ rotating frame using the Park transform described in the appendix. We make the assumption of a balanced three phase system, and 0 axis components are set to zero. The state space equations of the synchronous generator are given by:

$u d s=R s . i d s-w e .(L l s . i q s+L m q .(i q s+i k q))+\frac{d}{d t}(L l s . i d s+L m d .(i d s+i f d+i k d))$ $u q s=R s . i q s+w e .(L l s . i d s+L m d .(i d s+i f d+i k d))+\frac{d}{d t}(L l s . i q s+L m q .(i q s+i k q))$ $0=R k d \cdot i k d+L l k d \cdot \frac{d i k d}{d t}+L m d \cdot \frac{d}{d t} \cdot(i d s+i f d+i k d)$

$0=R k q \cdot i k q+L l k q \frac{d i k q}{d t}+L m q \cdot \frac{d}{d t}(i k q+i q s)$

$u f d=R f d . i f d+\frac{d}{d t}(L l f d i f d+L m d .(i d s+i f d+i k d))$

(uds, uqs) are the stator voltages, (ids, iqs) the stator currents, (ikd, ikq) the damping windings currents, ifd is the excitation current and ufd the excitation voltage of the generator. we is the electrical pulsation. The parameters are defined in the appendix.

\section{2) The diode rectifier model}

The approach presented in this paper is a semi-analytical modeling method, which was originally proposed and validated in [3]. It consists in considering the diode rectifier as a voltage gain to calculate $\mathrm{DC}$ side voltage from $\mathrm{AC}$ side voltage, and a current gain to obtain $\mathrm{AC}$ side current from DC side current.

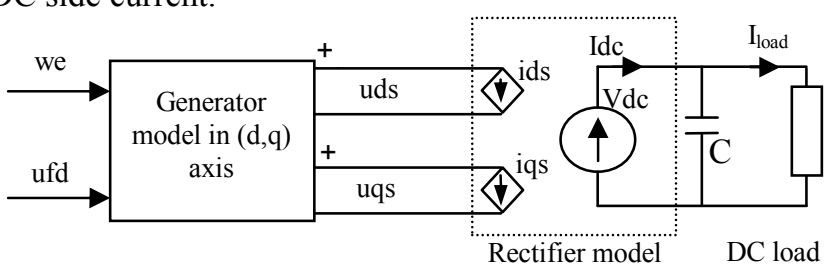

Fig. 3: Power source model [3]

The basic idea is to link the average values of the $(d, q)$ variables of the AC side to the average values of the DC side voltage and current $(2,3)$ :

$$
\begin{aligned}
& V d c=k v \cdot \sqrt{u d s^{2}+u q s^{2}} \\
& I d c=k i \cdot \sqrt{i d s^{2}+i q s^{2}}
\end{aligned}
$$

In these equations, kv and ki are voltage and current gains, which are nonlinear and depend on the operating point of the system [3]. The resulting space vector diagram is shown in Fig. 4:

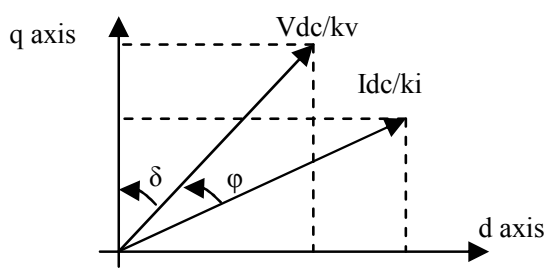

Fig. 4: space vector diagram for the rectifier model
From this diagram, the following equations are obtained:

$V d c=k v \cdot \sqrt{u d s^{2}+u q s^{2}}$

$i d s=\left(k_{\mathrm{cos}} \cdot u d s+k_{\mathrm{sin}} u q s\right) \cdot \frac{I d c}{V d c}$

iqs $=\left(k_{\mathrm{cos}} \cdot u q s-k_{\mathrm{sin}} u d s\right) \cdot \frac{I d c}{V d c}$

with:

$k_{\mathrm{cos}}=\frac{k v \cdot \cos \varphi}{k i}$ and $k_{\text {sin }}=\frac{k v \cdot \sin \varphi}{k i}$

In (7) and (8), $\varphi$ is the phase displacement between AC voltage and currents. To obtain the linear model of the rectifier, the above equations are linearized around the chosen operating point. The linear equations are given by:

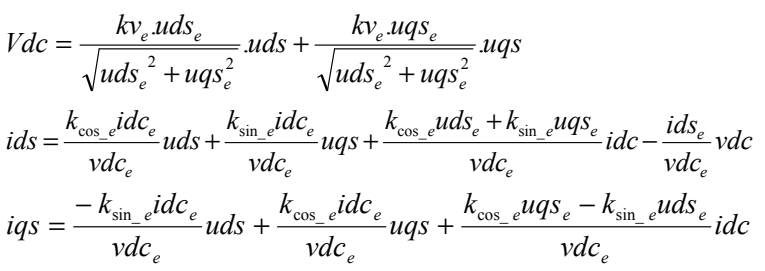

Index e denotes the equilibrium values of the variables. The following DC side equation is added to these equations:

$i d c=C \cdot \frac{d V d c}{d t}+i_{\text {load }}$

where $i_{\text {load }}$ is the load current.

3) State-space equations of the synchronous generator with diode rectifier system

To develop the model of the synchronous generator with the diode rectifier, the generator equations are associated to the rectifier equations. The load current is an input of the system and will be considered as the system disturbance for control design. The following representation is finally obtained:

$V \cdot U=E \cdot X+F \cdot \dot{X}$

with $\mathrm{U}$ the input vector, and $\mathrm{X}$ the state vector:

$U=\left[\begin{array}{ll}i_{\text {load }} & \text { ufd }\end{array}\right]^{T}$

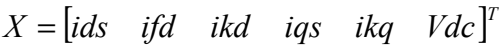

Matrix V, E and F are given by:

$V=\left[\begin{array}{cc}L_{21}+L_{22} L_{13} & 0 \\ 0 & 1 \\ 0 & 0 \\ L_{31}+L_{32} L_{13} & 0 \\ 0 & 0 \\ L_{13} & 0\end{array}\right]$

$E=\left[\begin{array}{cccccc}R s-L_{20}-L_{22} L_{11} & 0 & 0 & -w e L q-L_{22} L_{12} & -w e L m q & -L_{23}-L_{22} L_{10} \\ 0 & R f d & 0 & 0 & 0 & 0 \\ 0 & 0 & R k d & 0 & 0 & 0 \\ w e L d-L_{32} L_{11} & w e L m d & w e L m d & R s-L_{30}-L_{32} L_{12} & 0 & -L_{33}-L_{32} L_{10} \\ 0 & 0 & 0 & 0 & R k q & 0 \\ -L_{11} & 0 & 0 & -L_{12} & 0 & -L_{10}\end{array}\right]$ 


$F=\left[\begin{array}{cccccc}L d & L m d & L m d & 0 & 0 & 0 \\ L m d & L f & L m d & 0 & 0 & 0 \\ L m d & L m d & L D & 0 & 0 & 0 \\ 0 & 0 & 0 & L q & L m q & 0 \\ 0 & 0 & 0 & L m q & L Q & 0 \\ 0 & 0 & 0 & 0 & 0 & 1\end{array}\right]$

Coefficients $\mathrm{L}_{\mathrm{ij}}$ are quite complex and are not given in this paper. Then, the open-loop state-space representation of the system is obtained:

$\dot{X}=A . X+B . U$

$Y=C . X$

with :

$A=-F^{-1} \cdot E, B=F^{-1} \cdot V$, and $C=\left[\begin{array}{llllll}0 & 0 & 0 & 0 & 0 & 1\end{array}\right]$

\section{B. Control specifications}

\section{1) Disturbance rejection}

Following a load current step on the DC side of the rectifier, the standards usually impose that the DC voltage remains in a transient envelop defined by Fig. 5, as presented in [1].

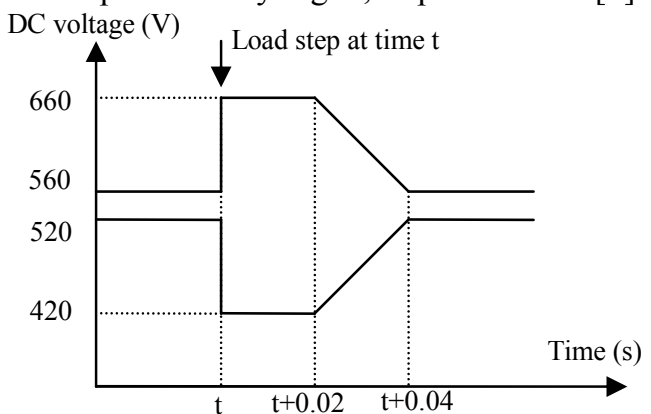

Fig. 5: Assigned transient envelop after a load step at Point Of Regulation

These specifications should be met for all operating conditions, which is a robust performance criterion.

\section{2) Limitations on the excitation voltage}

To avoid control saturation, the minimum / maximum amplitude of the excitation should be limited. Saturation limits are ufd $=0 \mathrm{~V}$ (the excitation voltage can not be negative) and ufd $=48 \mathrm{~V}$ (upper limit of saturation). The bandwidth of the control should also be limited for noise attenuation. In this application, the noise on the DC voltage measurement is the harmonic content of the DC voltage due to the 6-pulses rectification. This harmonic content is at frequency $\mathrm{fn}=6 * \mathrm{fe}$, with fe the frequency of the AC voltage. Consequently it varies from $2160 \mathrm{~Hz}(\mathrm{fe}=360 \mathrm{~Hz})$ to $4800 \mathrm{~Hz}$ $(\mathrm{fe}=800 \mathrm{~Hz})$.

\section{Ho CONTROL OF THE GENERATOR WITH DIODE RECTIFIER SYSTEM AT THE NOMINAL 400HZ OPERATING POINT}

In this section, the first part is devoted to a background on the $\mathrm{H} \infty$ control approach. The second one concerns the application of $\mathrm{H} \infty$ control theory to the system introduced in section II at the nominal operating condition of the system defined by fe $=400 \mathrm{~Hz}$. The performance of this $\mathrm{H} \infty$ controller will finally be evaluated for various operating conditions.

\section{A. Some background on $H \infty 0$ control}

The $\mathrm{H} \infty$ control problem relies on the general control configuration (Fig. 6), where $\mathrm{P}(\mathrm{s})$ is the generalized plant model. $v$ are the control variables, $y$ the measured variables, $w$ the exogenous signals and $e$ the controlled output variables. Given $\gamma$, a pre-specified attenuation level, a suboptimal $\mathrm{H} \infty$ control problem is to design a controller that internally stabilizes the closed-loop system and ensures:

$\left\|N_{e w}(s)\right\|_{\infty} \leq \gamma$

where $\mathrm{N}_{\mathrm{ew}}$ is the closed-loop transfer matrix from $e$ to $w$. Weights are considered to take the performance specifications in the frequency domain into account. In Fig. $6, \mathrm{G}$ is the plant model and $\mathrm{W}_{\mathrm{i} / \mathrm{o}}$ the frequency domain weights.

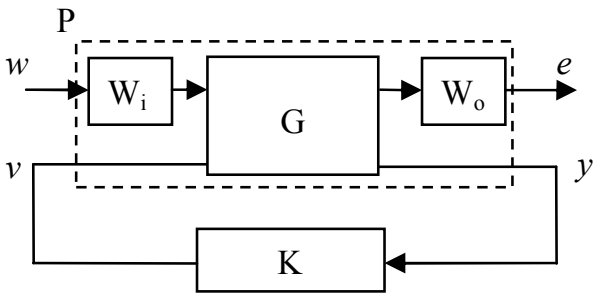

Fig. 6: General control configuration [4]

The Ho suboptimal control problem (17) is solved using the Riccati equations or LMI, allowing to get the minimal value of gamma. The details can be found in [4].

\section{B. Ho control design at the nominal $400 \mathrm{~Hz}$ frequency.}

In this part, the authors apply the $\mathrm{H} \infty$ control theory to the proposed power source. The operating point is set to $\mathrm{fe}=400 \mathrm{~Hz}$ at the maximum power point $(150 \mathrm{~kW}$, $\left.\mathrm{i}_{\text {load }}=270 \mathrm{~A}\right)$. The studied control configuration is presented in Fig. 7.

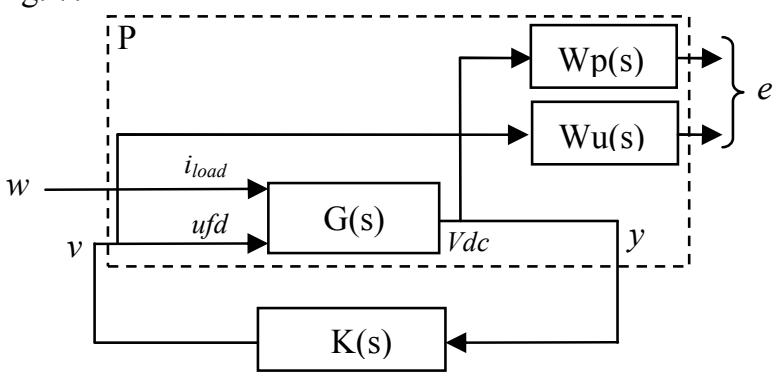

Fig. 7: the control scheme with the weights

It includes the plant model $\mathrm{G}(\mathrm{s})$, the controller to be designed $\mathrm{K}(\mathrm{s})$ and the weighting functions $\mathrm{Wp}(\mathrm{s})$ and $\mathrm{Wu}(\mathrm{s})$. $\mathrm{Wp}(\mathrm{s})$ is the frequency domain weight representing the required disturbance rejection performances. $\mathrm{Wu}(\mathrm{s})$ is the weight linked to the excitation voltage limitations explained upper. They are chosen as follows.

Wp: The inverse of the function $\mathrm{Wp}$ defines the template of the transfer function $V d c / i_{\text {load. }}$. This template should guarantee that after a load current step, the DC voltage remains in the envelop defined in Fig. 5. A maximum load current step of $135 \mathrm{~A}$ is considered (which corresponds to a - 
$50 \%$ load power step). The weighting function is given by:

$W p(s)=\frac{s / M s+w b}{s+w b \cdot \varepsilon s}$

with $\mathrm{Ms}=120 / 135, \mathrm{wb}=75 \mathrm{rad} / \mathrm{s}$ and $\varepsilon s \approx 0$.

Wu: The control input ufd is limited beyond $1000 \mathrm{~Hz}$ in order to avoid noise sensitivity. For fe $=400 \mathrm{~Hz}$, noise occurs at $6 * 400=2400 \mathrm{~Hz}$. Moreover, the amplitude of $\mathrm{Wu}$ is limited before $1000 \mathrm{~Hz}$ to avoid excitation voltage saturation. The weighting function $\mathrm{Wu}$ is given by:

$W u(s)=\frac{s+w b u / M u}{\varepsilon u . s+w b u}$

The Ho problem has a solution. This means that the control objectives are met at the operating point corresponding to $\mathrm{fe}=400 \mathrm{~Hz}$. The amplitudes of the obtained closed-loop transfer functions $V d c / i_{\text {load }}$ and $u f d / i_{\text {load }}$ are respectively given in Fig. 8 and Fig. 9 and compared to the templates $1 / \mathrm{Wp}$ and $1 / \mathrm{Wu}$.

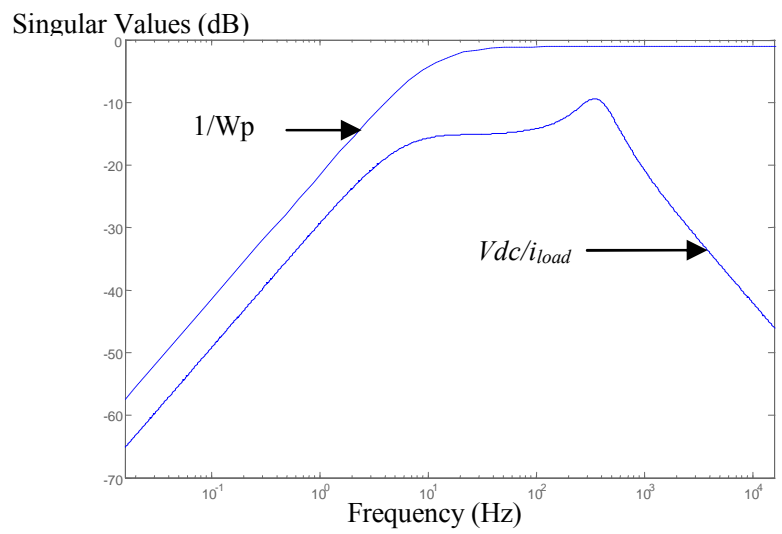

Fig. 8: Amplitude of the closed-loop transfer function $V d c / i_{\text {load }}$ and template $1 / \mathrm{Wp}$.

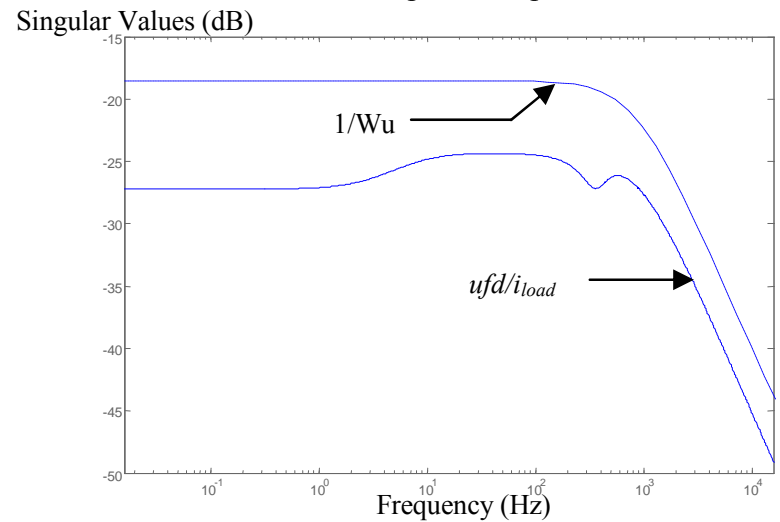

Fig. 9: Amplitude of the closed-loop transfer function $u f d / i_{\text {load }}$ and template $1 / \mathrm{Wu}$.

The controller performances are now evaluated at different operating conditions, for fe varying from $360 \mathrm{~Hz}$ to $800 \mathrm{~Hz}$. The closed-loop transfer function $V d c / i_{\text {load }}$ and $u f d / i_{\text {load }}$ are plotted for $\mathrm{fe}=360 \mathrm{~Hz}, 400 \mathrm{~Hz}, 500 \mathrm{~Hz}, 600 \mathrm{~Hz}$, $700 \mathrm{~Hz}$ and $800 \mathrm{~Hz}$ (Fig. 10 and 11).
Singular Values $(\mathrm{dB})$

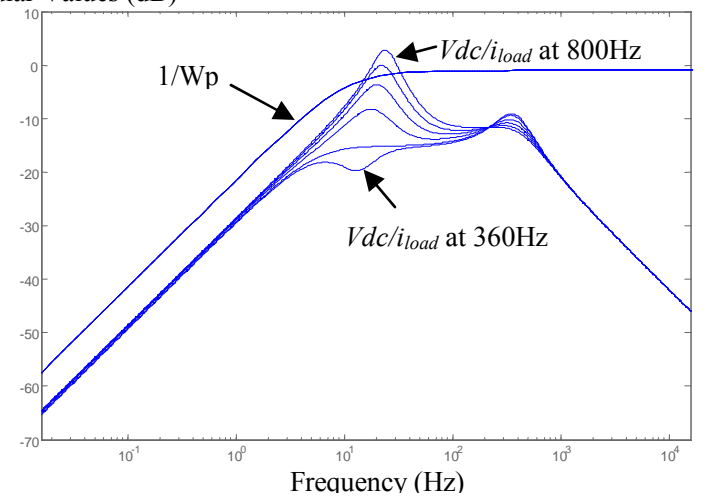

Fig. 10: Amplitude of the closed-loop transfer function $V d c / i_{\text {load }}$ for operating frequencies from $360 \mathrm{~Hz}$ to $800 \mathrm{~Hz}$ and $1 / \mathrm{Wp}$.

Singular Values (dB)

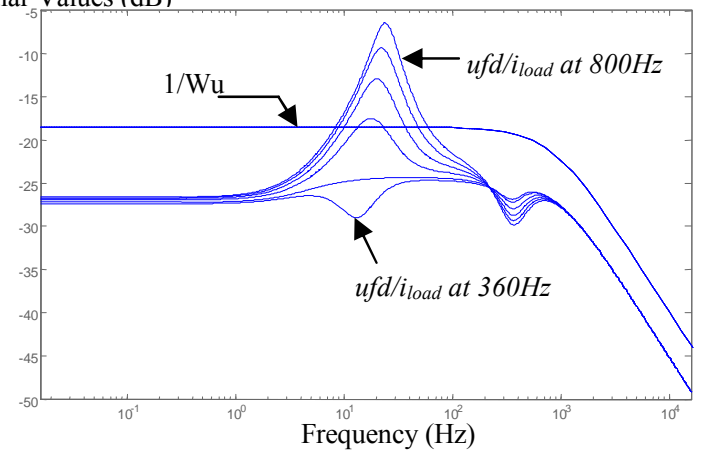

Fig. 11: Amplitude of the closed-loop transfer function $u f d / i_{\text {load }}$ for operating frequencies from $360 \mathrm{~Hz}$ to $800 \mathrm{~Hz}$ and template $1 / \mathrm{Wu}$.

The analysis of Fig. 10 and Fig. 11 shows that the required performances are not met for all the operating conditions of the system. It can also be concluded that the "worst" operating point is at high shaft speed, i.e. for fe $=800 \mathrm{~Hz}$. As a conclusion, a $\mathrm{H} \infty$ controller synthesized at $800 \mathrm{~Hz}$ that would meet the performances specifications would also meet the specifications for lower operating frequencies. In the next section, the authors look for such a controller.

\section{Hळ CONTROL DESIGN AT THE “WORST” OPERATING CONDITION}

\section{A. Performance specifications}

A controller designed at the "worst" operating condition ( $\mathrm{fe}=800 \mathrm{~Hz}$ ) would also meet the performance specifications for lower frequencies. As explained upper, the voltage measurement noise directly depends on the DC voltage harmonic level, which is caused by the 6-pulses rectification. It explains that the noise frequency varies from $2160 \mathrm{~Hz}$ to $4800 \mathrm{~Hz}$, according to the operating AC side frequency. To guarantee noise rejection at all operating frequencies, the control should not be sensitive to the noise which occurs at the frequency $6 * 360=2160 \mathrm{~Hz}$. For this, the cut off frequency in $\mathrm{Wu}$ is chosen to reject $2160 \mathrm{~Hz}$ noise. The required disturbance rejection performances are the same and the Wp parameters are not changed (18). 


\section{B. Ho control design at the "worst" operating condition}

The results are plotted in Fig. 12 and 13. The amplitudes of the closed-loop transfer functions $V d c / i_{\text {load }}$ and $u f d / i_{\text {load }}$ are compared to the templates $1 / \mathrm{Wp}$ and $1 / \mathrm{Wu}$.

Singular Values $(\mathrm{dB})$

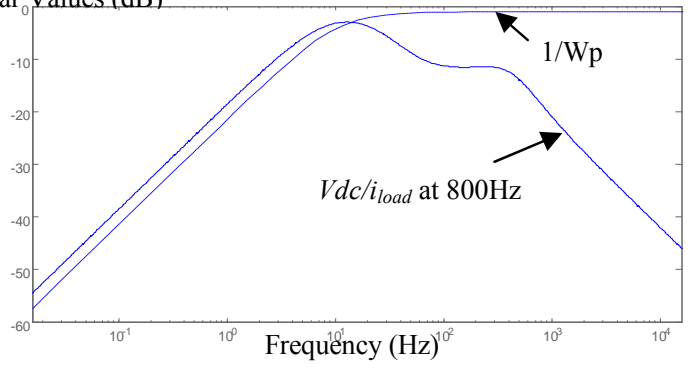

Fig. 12: Amplitude of the closed-loop transfer function $\mathrm{Vdc} / \mathrm{i}_{\text {load }}$ at the worst operating frequency $(800 \mathrm{~Hz})$ and $1 / \mathrm{Wp}$.

Singular Values (dB)

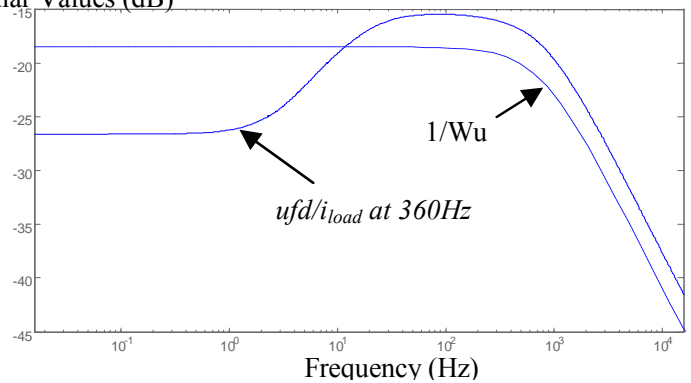

Fig. 13: Amplitude of the closed-loop transfer function $u f d / i_{\text {load }}$ at the worst operating frequency $(800 \mathrm{~Hz})$ and template $1 / \mathrm{Wu}$.

As shown on Fig. 12 and 13, the performance specifications are not met. From Fig. 12, it is concluded that a disturbance can not be rejected as fast as required. From Fig. 13, we notice that the resulting controller is sensitive to noise and exhibits saturation after a load step. This is a very important result because it shows that the performance requirements can not be simultaneously met for the "worst" operating condition. In other words, conflicting objectives were defined in the $\mathrm{H} \infty$ control problem (17). On one hand, from the analysis of the closed-loop transfer functions in Fig. 12 and 13, we conclude that the bandwidth and amplitude limitations on the excitation voltage are not compatible with the required disturbance rejection speed. On the other hand, the performance specifications on the excitation voltage can not be released for controller practical implementation reasons.

\section{Towards new performance specifications}

\section{1) Considerations on control achievability for usual disturbance rejection standards}

Other control solutions could be performed, for example a gain-scheduling control which would adapt the controller parameters to the AC side frequency. But it could be shown that at the operating $800 \mathrm{~Hz}$ condition, with the maximum admissible bandwidth on $1 / \mathrm{Wu}$ (chosen to reject noise at $6 * 800=4800 \mathrm{~Hz}$ ), no solutions can be found. Moreover, in more classical source structures [1], a simple PI control of the generator exhibits satisfying disturbance rejection performances and the standards are easily met. From these considerations, we conclude that the usual disturbance rejection standards are not suitable if the synchronous generator + diode rectifier source is chosen. In the next section, a new disturbance rejection standard is proposed. For this, the best performances achievable by an $\mathrm{H} \infty$ controller for all the operating conditions are sought.

\section{2) Best achievable performances by $H \infty$ control for all} the operating conditions

$\mathrm{Wu}$ is not changed (template of $1 / \mathrm{Wu}$ in Fig. 13) because they guarantee an adequate operation of the controller on the real plant (no noise sensitivity and no saturation). Only Wp is changed. We choose to keep almost the same requirements on over-voltage / under-voltage after the load step. But the required time response is extensively modified until the $\mathrm{H} \infty$ problem has a solution. The obtained closed-loop transfer functions are given in Fig. 14 and 15.

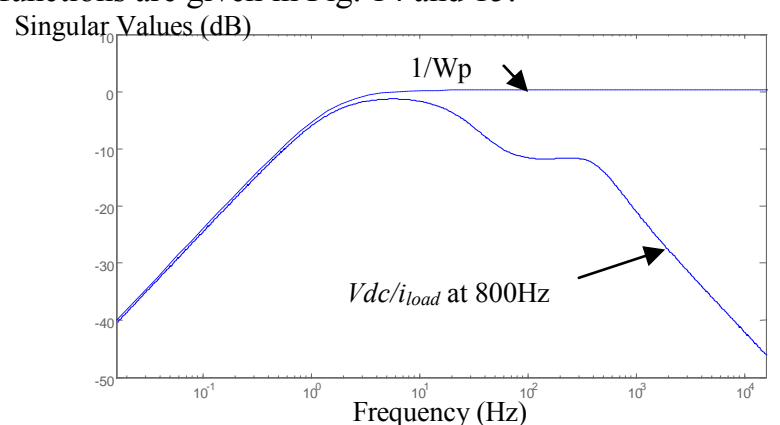

Fig. 14: Best achievable performance in 1/Wp and closed-loop transfer function $\mathrm{Vdc} / \mathrm{i}_{\text {load }}$ (Amplitudes).

Singular Values (dB)

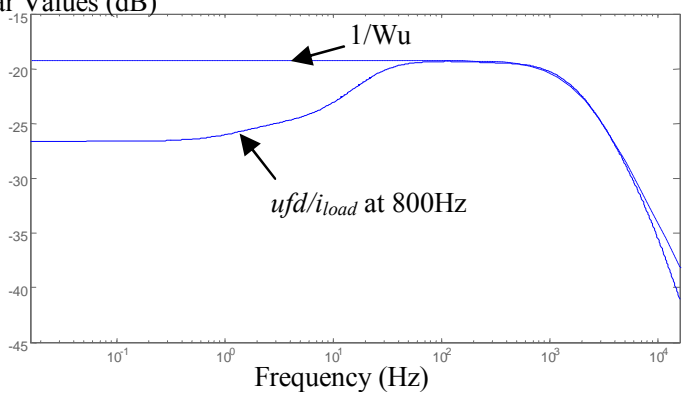

Fig. 15: Amplitude of the closed-loop transfer function $u f d / i_{\text {load }}$ and $1 / \mathrm{Wu}$

To find a solution to the $\mathrm{H} \infty$ problem, the cut-off frequency $w b$ of the $1 / \mathrm{Wp}$ template has been divided by 7,5 and the Ms factor in (18) was increased from $120 / 135$ to $140 / 135$. In other words, in the time domain the required time response is 7,5 times larger than with the classical requirements, and an overshoot of $140 \mathrm{~V}$ is allowed after a $135 \mathrm{~A}$ load step.

\section{Proposition of a new disturbance rejection standard}

Considering the results presented in this paper, the author propose to use the following disturbance rejection standard.

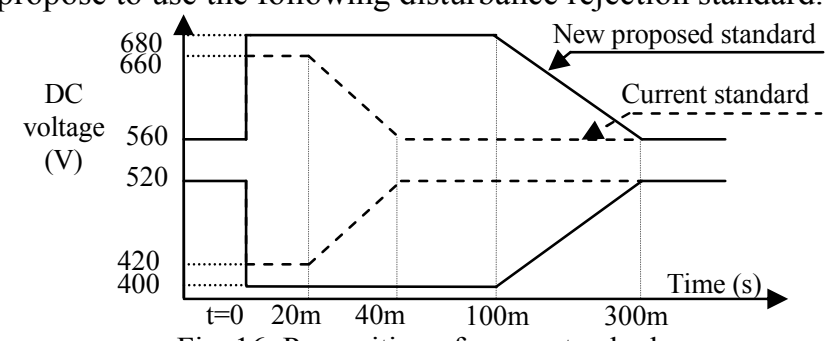

Fig. 16: Proposition of a new standard. 
This new performance specification is the translation of the frequency domain template $1 / \mathrm{Wp}$ into time domain performances.

\section{E. Validation by non-linear simulation}

Our approach is validated using the non-linear simulation tool SABER ${ }^{\circledR}$. The topological model presented in Fig. 2 is simulated, where the DC load is an ideal constant power load, which is a typical aircraft electrical load [1]. At $\mathrm{t}=0,5 \mathrm{~s}$, a load decrease from $150 \mathrm{~kW}$ (the nominal generator power) to $75 \mathrm{~kW}$ is simulated.

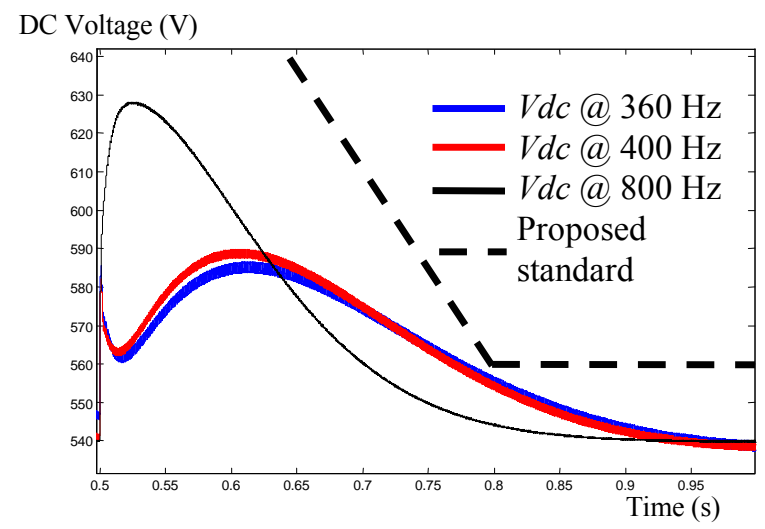

Fig. 17: DC voltage transient after a load power step from $150 \mathrm{~kW}$ to $75 \mathrm{~kW}$

Excitation Voltage (V)

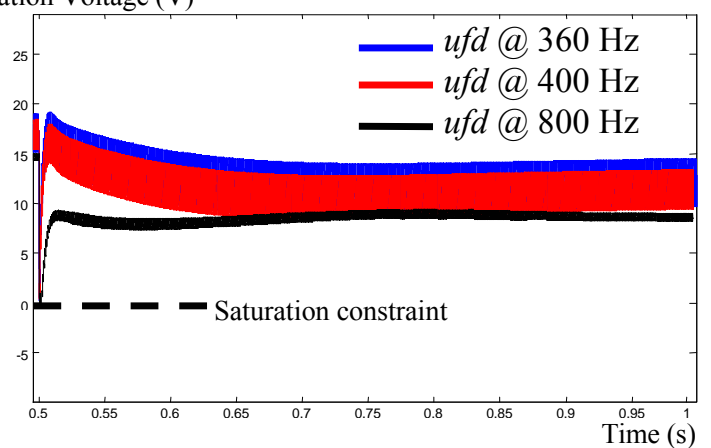

Fig. 18: Excitation voltage transient after a load power step from $150 \mathrm{~kW}$ to $75 \mathrm{~kW}$

As a conclusion, the new standard we propose in Fig. 16 is met. Moreover, no saturation appears after the load step and the maximal distortion of the excitation voltage is about $30 \%$ of the average value of $u f d$. This can be considered as being a maximum admissible value and lower noise desensitization performances would have been unacceptable. This supposes that the weighting function $\mathrm{Wu}$ was appropriately chosen from a practical implementation point of view.

\section{CONCLUSION}

This paper has dealt with the use of optimal $\mathrm{H} \infty$ control theory to prove that usual disturbance rejection standards can not be met for the studied aircraft power source. The best achievable frequency domain performances have then been found and translated in the time domain. This leads to the proposition of a new standard for aircraft power systems. This standard should be used if the synchronous generator + rectifier source is chosen for the future "All Electric" aircraft. This source has the advantage to be lighter than the power source studied in [1]. But using a more "relaxed" standard could lead to oversize other power elements (for example the breakers). Then the weight gain obtained by the use of the proposed power source may be compensated by an increase in other power elements weight. That is why other power sources will be studied in future publications. In particular, sources with less stringent bandwidth should be studied as a controlled rectifier, for example. For these other power sources, the best achievable performances will be searched from a $\mathrm{H} \infty$ control point of view and compared together.

\section{APPENDIX}

The Park transform is defined by:

$\left[\begin{array}{l}x_{d} \\ x_{q} \\ x_{0}\end{array}\right]=2 / 3 \times\left[\begin{array}{ccc}\cos w t & \cos (w t-2 \pi / 3) & \cos (w t+2 \pi / 3) \\ \sin w t & \sin (w t-2 \pi / 3) & \sin (w t+2 \pi / 3) \\ 1 / 2 & 1 / 2 & 1 / 2\end{array}\right]\left[\begin{array}{c}x_{a} \\ x_{b} \\ x_{c}\end{array}\right]$

where $\left(\mathrm{x}_{\mathrm{a}}, \mathrm{x}_{\mathrm{b}}, \mathrm{x}_{\mathrm{c}}\right)$ are the $\mathrm{AC}$ variables and $\left(\mathrm{x}_{\mathrm{d}}, \mathrm{x}_{\mathrm{q}}, \mathrm{x}_{0}\right)$ the rotating frame variables. The parameters of the power source are given in Table I:

TABLE I

SYSTEM PARAMETERS

\begin{tabular}{cll}
\hline \hline Symbol & \multicolumn{1}{c}{ Description } & Value \\
\hline$R s$ & Stator windings resistor & $11 \mathrm{~m} \Omega$ \\
Lls & Stator (d,q) axis leakage inductance & $25,1 \mu \mathrm{H}$ \\
Lmd & Stator d axis magnetizing inductance & $737 \mu \mathrm{H}$ \\
$L m q$ & Stator q axis magnetizing inductance & $659 \mu \mathrm{H}$ \\
$R k d$ & Resistance of d axis damper windings seen & $33 \mathrm{~m} \Omega$ \\
& from stator & \\
$R k q$ & Resistance of q axis damper windings seen & $44 \mathrm{~m} \Omega$ \\
& from stator & $3,6 \mathrm{~m} \Omega$ \\
$R f d$ & Resistance of exciter windings & $50,2 \mu \mathrm{H}$ \\
$L l k d$ & D axis damper leakage inductance & $14,9 \mu \mathrm{H}$ \\
$L l k q$ & Q axis damper leakage inductance & $159 \mu \mathrm{H}$ \\
$L l f d$ & Field winding leakage inductance & $2 \mathrm{mF}$ \\
$C$ & Output capacitor of the diode rectifier & $209 \mathrm{kVA}$ \\
$S n$ & Nominal power of the generator &
\end{tabular}

\section{ACKNOWLEDGMENT}

This research is being conducted in the frame of the MOET project, a FP6 European Integrated Project. The authors would like to thank MOET partners for model parameters and on board structure definition.

\section{REFERENCES}

[1] M. Sautreuil, N. Retière, D. Riu, O. Sename. "A generic method for robust performance analysis of aircraft DC power systems," presented at the $34^{\text {th }}$ Annual Conference of the IEEE Industrial Electronics Society IECON'08, 2008

[2] More Open Electrical Technologies (MOET) project web site, http://www.moetproject.eu

[3] I. Jadric, D. Borojevic, M. Jadric, "Modeling and control of a Synchronous generator with an active DC load", IEEE Trans. on Power Electronics, vol. 15, NO. 2, March 2000.

[4] S. Skogestad, I. Postlethwaite, "Multivariable Feedback Control: Analysis and Design", John Wiley and Sons, 2005. 